\title{
ON THE METHOD FOR THE SOLUTION OF ONE PROBLEM OF THE ELASTICITY THEORY
}

\section{V.R. KRISTALINSKII}

Smolensk State Pedagogical University

214000 Smolensk, Russia

E-mail: icspgu@sci.smolensk.ru

Received September 17, 2002; revised February 7, 2003

\section{ABSTRACT}

This paper is devoted to a method of obtaining the equation describing the bend of the round fixed plate under the loading, concentrated at the point and on the interior circumference.

Key words: bend of the round fixed plate, Gilbert boundary value problem

\section{THE SOLUTION OF THE GILBERT BOUNDARY VALUE PROBLEM FOR ROUND REGION}

Let us consider the following problem. It is required to find all real valued byharmonic in $T^{+}$functions $U(x, y)$, continuous in $T^{+} \cup L$ with their partial derivatives of the first order and satisfying on $L$ the following conditions:

$$
\frac{\partial U}{\partial x}=c_{1}(t), \quad \frac{\partial U}{\partial y}=c_{2}(t)
$$

where $c_{1}(t), c_{2}(t)$ are given real-valued functions, belonging to the class $H^{1}(L)$.

The problem (1.1) is a special case of the so-called Gilbert-type boundary value problem for byanalitic functions

$$
\left\{\begin{array}{l}
a_{1}(t) \frac{\partial u}{\partial x}+b_{1}(t) \frac{\partial v}{\partial x}=c_{1}(t) \\
a_{2}(t) \frac{\partial u}{\partial y}+b_{2}(t) \frac{\partial v}{\partial y}=c_{2}(t)
\end{array}\right.
$$

where $a_{k}(t), b_{k}(t), c_{k}(t)(k=1,2)$ are given real valued functions of the complex argument, satisfying on $L$ the Holder condition with their derivatives 
up to the order $(3-k)$, and $\left[a_{k}(t)\right]^{2}+\left[b_{k}(t)\right]^{2}=1$. So, we can obtain the solution of the problem (1.1) from formulae for (1.2). As an example, let us obtain the solution of problem (1.1) for the round regions.

The solution of problem (1.2) is being searched in the form

$$
F(z)=\varphi_{0}(z)+\bar{z} \varphi_{1}(z)
$$

where $\phi_{0}(z), \phi_{1}(z)$ are analytic functions in the circle $K_{1}$. Then the solution of problem (1.1) can be obtained by the formula

$$
U(x, y)=\operatorname{Re}\left[\varphi_{0}(z)+\bar{z} \varphi_{1}(z)\right] .
$$

We see, that the values of imaginary parts of $\phi_{0}(z)$ and $\bar{z} \phi_{1}(z)$ do not influence the solution of problem (1.1). So without the restriction on generality we can suppose, that the following initial conditions are fulfilled:

$$
\operatorname{Im} \varphi_{0}(0)=0, \quad \varphi_{1}(0), \quad \operatorname{Im} \varphi_{1}^{\prime}=0 .
$$

Then we can rewrite the boundary conditions of problem (1.2):

$$
\begin{aligned}
& \varphi_{0}^{\prime}(t)+\bar{t} \varphi_{1}^{\prime}(t)+\varphi_{1}(t)=-\left[\overline{\varphi_{0}^{\prime}(t)}+\overline{t \varphi_{1}^{\prime}(t)}+\overline{\varphi_{1}(t)}\right]+2 c_{1}(t) \\
& \varphi_{0}^{\prime}(t)+\bar{t} \varphi_{1}^{\prime}(t)-\varphi_{1}(t)=-\left[\overline{\varphi_{0}^{\prime}(t)}+\overline{t \varphi_{1}^{\prime}(t)}-\overline{\varphi_{1}(t)}\right]-2 i c_{2}(t)
\end{aligned}
$$

Using notation

$$
\Phi(z)=\varphi_{0}^{\prime}(z), Q_{1}(z)=-\bar{t} \varphi_{1}^{\prime}(t)-\varphi_{1}(t)-\bar{t} \overline{\varphi_{1}^{\prime}(t)}-\overline{\varphi_{1}(t)}+2 c_{1}(t),
$$

we can rewrite the boundary condition of (1.4) as

$$
\Phi_{0}(t)=-\overline{\Phi_{0}(t)}+Q_{1}(t) .
$$

In the case of circle $K_{1}$ the kernel

$$
K(t, \tau)=\frac{1}{2 \pi i}\left[\frac{1}{\tau-t}-\frac{\left[\tau^{\prime}(\sigma)\right]^{2}}{\bar{\tau}-\bar{t}}\right]
$$

of the integral equation

$$
\mu_{0}(t)+\frac{1}{2 \pi i} \int_{L} K(t, \tau) \mu_{0}(\tau) d \tau=Q_{1}(t)
$$

is defined by the formula

$$
K(t, \tau)=\frac{1}{2 \pi i} \frac{1}{\tau}
$$


On the method for the solution of one problem of the elasticity theory 133

and its resolvent $R_{10}(t, \tau)=-4 \pi i / \tau$.

Considering temporarily $Q_{1}(\tau)$ as the known function and solving the Gilbert boundary value problem (1.7) with the coefficient $G_{1}(t)=-1$ we obtain

$$
\Phi_{0}(z)=\frac{1}{2 \pi i} \int_{\gamma_{1}} \frac{Q_{1}(\tau)}{\tau-z} d \tau-\frac{1}{4 \pi i} \int_{\gamma_{1}} \frac{Q_{1}(\tau)}{\tau} d \tau+i \epsilon_{0},
$$

where $\epsilon_{0}$ is an arbitrary real constant.

Substituting in (1.8) for $Q_{1}(\tau)$ its value from (1.6) we obtain

$$
\begin{aligned}
\Phi_{0}(z)=-\frac{\varphi_{1}^{\prime}(z)}{z}-\varphi_{1}(z)+ & \frac{\varphi_{1}^{\prime}(0)}{z}-z \overline{\varphi_{1}^{\prime}(0)}+i \operatorname{Im} \varphi_{1}(0)+i \operatorname{Im} \varphi_{1}^{\prime \prime}(0) \\
& +\frac{1}{\pi i} \int_{\gamma_{1}} \frac{c_{1}(\tau)}{\tau-z} d \tau-\frac{1}{2 \pi i} \int_{\gamma_{1}} \frac{c_{1}(\tau)}{\tau} d \tau+i \epsilon_{0} .
\end{aligned}
$$

Passing on to the limit by $z \rightarrow t \in \gamma_{1}$ and taking into consideration (1.3) we obtain from (1.9) that

$$
\begin{aligned}
\Phi_{0}(t) & =-\bar{t} \varphi_{1}^{\prime}(t)-\varphi_{1}(t)-2 i \operatorname{Im}\left\{\overline{t \varphi_{1}^{\prime}(0)}\right\}+i \operatorname{Im} \varphi_{1}^{\prime \prime}(0) \\
& +c_{1}(t)+\frac{1}{\pi i} \int_{\gamma_{1}} \frac{c_{1}(\tau)}{\tau-t} d \tau-\frac{1}{2 \pi i} \int_{\gamma_{1}} \frac{c_{1}(\tau)}{\tau} d \tau+i \epsilon_{0}, \\
\overline{\Phi_{0}(t)} & =-\overline{t \varphi_{1}^{\prime}(t)}-\overline{\varphi_{1}(t)}-2 i \operatorname{Im}\left\{\overline{t \varphi_{1}^{\prime}(0)}\right\}+i \operatorname{Im} \varphi_{1}^{\prime \prime}(0) \\
& +c_{1}(t)-\frac{1}{\pi i} \int_{\gamma_{1}} \frac{c_{1}(\tau)}{\tau-t} d \tau+\frac{1}{2 \pi i} \int_{\gamma_{1}} \frac{c_{1}(\tau)}{\tau} d \tau-i \epsilon_{0} .
\end{aligned}
$$

Substituting in (1.5) for $\varphi_{0}^{\prime}(t)=\Phi_{0}(t)$ and $\overline{\varphi_{0}^{\prime}(t)}=\overline{\Phi_{0}(t)}$ their values from (1.10) and (1.11) we get

$$
\phi_{1}(t)=\overline{\phi_{1}(t)}+Q_{2}(t)
$$

where

$$
\begin{aligned}
Q_{2}(t)=\frac{1}{\pi i} \int_{\gamma_{1}} \frac{c_{1}(\tau)}{\tau-t} d \tau-\frac{1}{2 \pi i} \int_{\gamma_{1}} \frac{c_{1}(\tau)}{\tau} d \tau+i c_{2}(t) \\
+2 i \operatorname{Im}\left\{\bar{t} \varphi_{1}^{\prime}(0)\right\}+i \operatorname{Im}\left\{\bar{t} \varphi_{1}^{\prime \prime}(0)\right\}+i \epsilon_{0} .
\end{aligned}
$$

Considering temporarily $Q_{2}(t)$ as the known function and solving the Gilbert boundary value problem (1.12) with the coefficient $G_{2}(t)=1$, we obtain

$$
\varphi_{1}(z)=\frac{1}{2 \pi i} \int_{\gamma_{1}} \frac{Q_{2}(\tau)}{\tau-z} d \tau-\frac{1}{4 \pi i} \int_{\gamma_{1}} \frac{Q_{2}(\tau)}{\tau} d \tau+\epsilon_{1},
$$


where $\epsilon_{1}$ is an arbitrary real constant.

Substituting in the right-hand side of (1.14) for $Q_{2}(t)$ its value from (1.13), we get the equality

$$
\begin{aligned}
\varphi_{1}(z)=\frac{1}{2 \pi i} \int_{\gamma_{1}} \frac{c_{1}(\tau)+i c_{2}(\tau)}{\tau-z} d \tau-\frac{1}{4 \pi i} \int_{\gamma_{1}} \frac{c_{1}(\tau)+i c_{2}(\tau)}{\tau} d \tau \\
\quad-\frac{1}{4 \pi i} \int_{\gamma_{1}} \frac{c_{1}(\tau)}{\tau} d \tau+\frac{i}{2} \operatorname{Im} \varphi_{0}^{\prime \prime}(0)+\frac{i}{2} \epsilon_{0}+\epsilon_{1}-z \overline{\varphi_{0}^{\prime}(z)} .
\end{aligned}
$$

Taking into account that $\varphi_{1}(0)=0$ and setting $z=0$ from (1.15) we obtain

$$
0=\frac{1}{4 \pi i} \int_{\gamma_{1}} \frac{i c_{2}(t)}{\tau} d \tau+\frac{i}{2} \epsilon_{0}+\epsilon_{1}
$$

But the last equation is equivalent to the system

$$
\left\{\begin{array}{l}
l \epsilon_{1}=0 \\
\epsilon_{0}=-\operatorname{Im} \varphi_{1}^{\prime \prime}(0)-\frac{1}{2 \pi i} \int_{\gamma_{1}} \frac{c_{2}(\tau)}{\tau} d \tau
\end{array}\right.
$$

Taking into consideration (1.16) we can obtain from (1.15)

$$
\varphi_{1}(z)=-\frac{1}{2 \pi i} \int_{\gamma_{1}} \frac{c_{1}(\tau)+i c_{2}(\tau)}{\tau-z} d \tau-\frac{1}{2 \pi i} \int_{\gamma_{1}} \frac{c_{1}(\tau)+i c_{2}(\tau)}{\tau} d \tau-z \overline{\varphi_{0}^{\prime}(0)} .
$$

Differentiating equation (1.17) we have

$$
\varphi_{1}^{\prime}(z)=\frac{1}{2 \pi i} \int_{\gamma_{1}} \frac{c_{1}(\tau)+i c_{2}(\tau)}{(\tau-z)^{2}} d \tau-\overline{\varphi_{1}^{\prime}(0)} .
$$

Substituting in (1.18) $z=0$ we obtain

$$
\varphi_{1}^{\prime}(0)+\overline{\varphi_{1}^{\prime}(0)}=\frac{1}{2 \pi i} \int_{\gamma_{1}} \frac{c_{1}(\tau)+i c_{2}(\tau)}{\tau^{2}} d \tau
$$

But equation (1.19) can take place if and only if

$$
\operatorname{Im}\left\{\frac{1}{2 \pi i} \int_{\gamma_{1}} \frac{c_{1}(\tau)+i c_{2}(\tau)}{\tau^{2}} d \tau\right\}=0
$$


Let us permit that condition (1.20) is fulfilled. Then, from (1.17), (1.18), taking into consideration (1.19) and the equation $\operatorname{Im} \varphi_{1}^{\prime}(0)=0$ we obtain

$$
\begin{aligned}
\varphi_{1}(z) & =\frac{1}{2 \pi i} \int_{\gamma_{1}} \frac{c_{1}(\tau)+i c_{2}(\tau)}{\tau-z} d \tau \\
- & \frac{1}{2 \pi i} \int_{\gamma_{1}} \frac{c_{1}(\tau)+i c_{2}(\tau)}{\tau} d \tau-\frac{z}{4 \pi i} \int_{\gamma_{1}} \frac{c_{1}(\tau)+i c_{2}(\tau)}{\tau^{2}} d \tau \\
\varphi_{1}^{\prime}(z) & =\frac{1}{2 \pi i} \int_{\gamma_{1}} \frac{c_{1}(\tau)+i c_{2}(\tau)}{(\tau-z)^{2}} d \tau-\frac{1}{4 \pi i} \int_{\gamma_{1}} \frac{c_{1}(\tau)+i c_{2}(\tau)}{\tau^{2}} d \tau
\end{aligned}
$$

Since $c_{1}(t), c_{2}(t) \in H^{(1)}\left(\gamma_{1}\right)$ we can rewrite the formula (1.22) as:

$$
\begin{aligned}
\varphi_{1}^{\prime}(z)=\frac{1}{2 \pi i} \int_{\gamma_{1}} \frac{c_{1}^{\prime}(\tau)-i c_{2}^{\prime}(\tau)}{\tau-z} d \tau \\
\quad-\frac{z^{-1}}{2 \pi i} \int_{\gamma_{1}} \frac{c_{1}(\tau)+i c_{2}(\tau)}{(\tau-z)^{2}} d \tau+\frac{z^{-1}}{2 \pi i} \int_{\gamma_{1}} \frac{c_{1}(\tau)+i c_{2}(\tau)}{\tau^{2}} d \tau .
\end{aligned}
$$

Then substituting in $Q_{1}(\tau)$ of the boundary condition (1.7) for $\varphi_{1}(t), \overline{\varphi_{1}(t)}$, $\varphi_{1}^{\prime}(t), \overline{\varphi_{1}^{\prime}(t)}$ the boundary values of functions found by formulae (1.21) and $(1.22) \varphi_{1}(z), \varphi_{1}^{\prime}(z)$ and solving the boundary value problem (1.7) we have

$$
\begin{aligned}
\Phi_{0}(z)=\frac{1}{2 \pi i} \int_{\gamma_{1}} \frac{c_{1}(\tau)-i c_{2}(\tau)}{\tau-z} d \tau+\frac{z^{-1}}{2 \pi i} \int_{\gamma_{1}} \frac{c_{1}(\tau)+i c_{2}(\tau)}{(\tau-z)^{2}} d \tau \\
+\frac{z^{-1}}{2 \pi i} \int_{\gamma_{1}} \frac{c_{1}(\tau)+i c_{2}(\tau)}{\tau^{2}} d \tau .
\end{aligned}
$$

Then with the help of integration and taking into consideration (1.3) we have

$$
\begin{array}{r}
\phi_{0}(z)=\int_{\Gamma}\left\{\frac{1}{2 \pi i} \int_{\gamma_{1}} \frac{c_{1}(\tau)-i c_{2}(\tau)}{\tau-z} d \tau+\frac{z^{-1}}{2 \pi i} \int_{\gamma_{1}} \frac{c_{1}(\tau)+i c_{2}(\tau)}{(\tau-z)^{2}} d \tau\right. \\
\left.+\frac{z^{-1}}{2 \pi i} \int_{\gamma_{1}} \frac{c_{1}(\tau)+i c_{2}(\tau)}{\tau^{2}} d \tau\right\} d z+\delta_{0},
\end{array}
$$

where $\Gamma$ is an arbitrary smooth curve, belonging to circle $K_{1}$ and connecting points 0 and $z$, and $\delta_{0}$ is an arbitrary real constant. Then we can determine 
function $F(z)$ by the formula

$$
F(z)=\varphi_{0}(z)+\bar{z} \varphi_{1}(z)
$$

where $\varphi_{0}(z)$ and $\varphi_{1}(z)$ are determined by formulae (1.23) and (1.21), respectively. This result was published in [3].

\section{A METHOD FOR OBTAINING THE EQUATION OF THE BEND OF THE ROUND FIXED PLATE UNDER THE LOAD- ING}

Let us apply this result to the solution of the following problem: find the equation of the bend of the round fixed plate under the concentrated loading $P$, applied at the point $M_{0}\left(z_{0}\right)$.

It is known, that the equation of the bend of such a plate has a form

$$
w=w(z)
$$

where $w(x, y)$ satisfies the differential equation

$$
\Delta^{2} w=\frac{P}{D} \delta\left(z-z_{0}\right)
$$

Here $D$ is the rigidity of the plate with the flexure, $\delta(z)$ is the Dirac function, and also the following boundary conditions are fulfilled for the function $w(x, y)$

$$
\left.w\right|_{|z|=1}=0 ;\left.\quad \frac{\partial w}{\partial x}\right|_{|z|=1}=0 ;\left.\quad \frac{\partial w}{\partial y}\right|_{|z|=1}=0 .
$$

We search for the solution of the equation (31) in the form

$$
w=\tilde{u}+w_{0},
$$

where $\tilde{u}(x, y)$ is a byharmonic function,

$$
w_{0}=\frac{P}{16 \pi D}\left(z-z_{0}\right)\left(\bar{z}-\bar{z}_{0}\right) \cdot \ln \left(\left(z-z_{0}\right)\left(\bar{z}-\bar{z}_{0}\right)\right) .
$$

Function $w_{0}(z)$ is a special solution of the equation (2.1) (see [2], p. 379). Then function $u(x, y)=\frac{16 \pi D}{P} \tilde{u}(x, y)$ satisfies the following boundary conditions

$$
\begin{aligned}
& \left.c_{1}(t)\right|_{|t|=1}=\left.\frac{\partial u}{\partial x}\right|_{|t|=1}=-2 \operatorname{Re}\left[\left(t-z_{0}\right)\left(1+\ln \left(\left(t-z_{0}\right)\left(\bar{t}-\bar{z}_{0}\right)\right)\right)\right] \\
& \left.c_{2}(t)\right|_{|t|=1}=\left.\frac{\partial u}{\partial y}\right|_{|t|=1}=-2 \operatorname{Im}\left[\left(t-z_{0}\right)\left(1+\ln \left(\left(t-z_{0}\right)\left(\bar{t}-\bar{z}_{0}\right)\right)\right)\right] .
\end{aligned}
$$


On the method for the solution of one problem of the elasticity theory 137

Let us compute the integral

$$
\frac{1}{2 \pi i} \int_{\gamma_{1}} \frac{c_{1}(t)+i c_{2}(t)}{t-z} d t
$$

Substituting their values of $c_{1}(t)$ and $c_{2}(t)$ from (2.2), we obtain

$$
\begin{aligned}
-2 \frac{1}{2 \pi i} \int_{\gamma_{1}} \frac{\left(t-z_{0}\right)\left(1+\ln (t-z)\left(\bar{t}-\bar{z}_{0}\right)\right)}{t-z} d t \\
\quad=2 \frac{1}{2 \pi i} \int_{\gamma_{1}} \frac{\left(t-z_{0}\right)\left(1+\ln (t-z)\left(\frac{1}{t}-\bar{z}_{0}\right)\right)}{t-z} d t \\
=2 \frac{1}{2 \pi i} \int_{\gamma_{1}} \frac{\left(t-z_{0}\right)\left(1+\ln \left(1-t \bar{z}_{0}\right) \cdot \ln \left(1-\frac{z_{0}}{t}\right)\right)}{t-z} d t \\
\quad=-2\left[\frac{1}{2 \pi i} \int_{\gamma_{1}} \frac{\left(t-z_{0}\right)\left(1+\ln \left(1-t \bar{z}_{0}\right)\right)}{t-z} d t\right. \\
\left.\quad+\frac{1}{2 \pi i} \int_{\gamma_{1}} \frac{\left(t-z_{0}\right)\left(\frac{z_{0}}{t}+\frac{z_{0}^{2}}{2 t^{2}}+\cdots\right)}{t-z} d t\right] .
\end{aligned}
$$

The first integral, as the integral from function, analytic in the circle $K_{1}$, is equal to

$$
\left(z-z_{0}\right)\left(1+\ln \left(1-z \cdot \bar{z}_{0}\right)\right) .
$$

We compute the second integral, applying the theorem about the residues. It is equal to $z_{0}$. Consequently,

$$
\frac{1}{2 \pi i} \int_{\gamma_{1}} \frac{c_{1}(t)+i c_{2}(t)}{t-z} d t=-2\left[\left(z-z_{0}\right)\left(1+\ln \left(1-\bar{z}_{0} \cdot z\right)+z_{0}\right)\right] .
$$

Hence we easily obtain

$$
\begin{aligned}
& \frac{1}{2 \pi i} \int_{\gamma_{1}} \frac{c_{1}(t)+i c_{2}(t)}{(t-z)^{2}} d t=-2\left[1-\frac{\bar{z}_{0}\left(z-z_{0}\right)}{1-\bar{z}_{0} \cdot z}+\ln \left(1-\bar{z}_{0} \cdot z\right)\right], \\
& \frac{1}{2 \pi i} \int_{\gamma_{1}} \frac{c_{1}(t)+i c_{2}(t)}{t} d t=0, \\
& \frac{1}{2 \pi i} \int_{\gamma_{1}} \frac{c_{1}(t)+i c_{2}(t)}{t^{2}} d t=-2\left(1+\left|z_{0}\right|^{2}\right) .
\end{aligned}
$$


Let us compute the integral

$$
\frac{1}{2 \pi i} \int_{\gamma_{1}} \frac{c_{1}(t)-i c_{2}(t)}{t-z} d t
$$

Substituting the values of $c_{1}(t)$ and $c_{2}(t)$, we obtain

$$
\begin{aligned}
& -2 \cdot \frac{1}{2 \pi i} \int_{\gamma_{1}} \frac{\left(\bar{t}-\bar{z}_{0}\right)\left(1+\ln \left(\left(\bar{t}-\bar{z}_{0}\right)\left(t-z_{0}\right)\right)\right)}{t-z} d t \\
& =-2 \cdot \frac{1}{2 \pi i} \int_{\gamma_{1}} \frac{\left(\frac{1}{t}-\bar{z}_{0}\right)\left(1+\ln \left(\left(1-\frac{z_{0}}{t}\right) \cdot\left(1-t \cdot \bar{z}_{0}\right)\right)\right)}{t-z} d t \\
& =-2 \cdot \frac{1}{2 \pi i} \int_{\gamma_{1}} \frac{\left(\frac{1}{t}-\bar{z}_{0}\right)\left(1+\ln \left(1-t \bar{z}_{0}\right)++\frac{z_{0}}{t}+\frac{z_{0}^{2}}{2 t^{2}}+\cdots\right)}{t-z} d t .
\end{aligned}
$$

Applying the theorem about the residues, we obtain

$$
\frac{1}{2 \pi i} \int_{\gamma_{1}} \frac{c_{1}(t)-i c_{2}(t)}{t-z} d t=-2\left[\bar{z}_{0}+\left(-\bar{z}_{0}+\frac{1}{z}\right) \ln \left(1-\bar{z}_{0} z\right)\right] .
$$

Now let us find the function

$$
\begin{aligned}
\varphi_{1}(z)= & \frac{1}{2 \pi i} \int_{\gamma_{1}} \frac{c_{1}(\tau)+i c_{2}(\tau)}{\tau-z} d \tau-\frac{1}{2 \pi i} \int_{\gamma_{1}} \frac{c_{1}(\tau)+i c_{2}(\tau)}{\tau} d \tau \\
& -\frac{z}{4 \pi i} \int_{\gamma_{1}} \frac{c_{1}(\tau)+i c_{2}(\tau)}{\tau^{2}} d \tau \\
& =-2\left[z_{0}+\left(z-\bar{z}_{0}\right)\left(1+\ln \left(1-z \bar{z}_{0}\right)-\frac{z\left(1+\left|z_{0}\right|^{2}\right)}{2}\right)\right] \\
& =z-\left|z_{0}\right|^{2} z-2 z \ln \left(1-z \bar{z}_{0}\right)+2 z_{0} \ln \left(1-z \bar{z}_{0}\right) .
\end{aligned}
$$

After the elementary transformations we obtain

$$
\begin{array}{r}
\frac{1}{2 \pi i} \int_{\gamma_{1}} \frac{c_{1}(t)-i c_{2}(t)}{t-z} d t-\frac{z^{-1}}{2 \pi i} \int_{\gamma_{1}} \frac{c_{1}(t)+i c_{2}(t)}{(t-z)^{2}} d t+\frac{z^{-1}}{2 \pi i} \int_{\gamma_{1}} \frac{c_{1}(t)+i c_{2}(t)}{t^{2}} d t \\
=-2\left(\frac{\bar{z}_{0}^{2} \cdot z-\bar{z}_{0}^{2} \cdot z_{0}}{1-\bar{z}_{0} \cdot z}-\bar{z}_{0} \ln \left(1-\bar{z}_{0} \cdot z\right)\right) \cdot
\end{array}
$$


It follows from (2.3), that

$$
\varphi_{0}(z)=2\left(\bar{z}_{0} z \ln \left(1-\bar{z}_{0} z\right)-\left|z_{0}\right|^{2} \ln \left(1-\bar{z}_{0} z\right)\right)+1-\left|z_{0}\right|^{2} .
$$

Hence

$$
\begin{array}{r}
\varphi_{0}(z)+\bar{z} \varphi_{1}(z)=2\left(\bar{z}_{0} z \cdot \ln \left(1-\bar{z}_{0} z\right)-\left|z_{0}\right|^{2} \ln \left(1-\bar{z}_{0} z\right)\right)+1-z^{2} \\
\quad+\bar{z}\left(-z+z_{0}^{2} z-2\left(z-z_{0}\right) \ln \left(1-\bar{z}_{0} z\right)\right. \\
=\left(1-\left|z_{0}\right|^{2}\right)\left(1-|z|^{2}-\left|z-z_{0}\right|^{2} \ln \left(1-\bar{z}_{0} z\right)^{2}\right) .
\end{array}
$$

Consequently

$$
u(x, y)=\operatorname{Re}\left(\varphi_{0}(z)+\bar{z} \varphi_{1}(z)\right)=\left(1+\left|z_{0}\right|^{2}\right)\left(1-|z|^{2}\right)-\left|z-z_{0}\right|^{2} \ln \left(1-\bar{z}_{0} z\right)^{2}
$$

Hence the equation of the blend of the plate has a form

$$
w(x, y)=\frac{P}{16 \pi D}\left[\left(1-\left|z_{0}\right|^{2}\right)\left(1-|z|^{2}\right)\right]+\ln \left|\frac{z-z_{0}}{1-\bar{z}_{0} z}\right|^{2} .
$$

In order to obtain the equation of the round fixed plate of radius $r$ we must substitute in (2.1) $\frac{z}{r}$ for $z$ and $\frac{z_{0}}{r}$ for $z_{0}$. Another proof of this result can be found in [5]. Let us find the equation of the blend of the fixed round plate of radius 1 , if the loading is concentrated on the interior circumference $\gamma$ with the intensity $P$. The case of circumference $\gamma$, which is concentric with the plate, was considered in [4]. Let us use the Cartesian coordinate system and suppose that the center of the plate coincides with the beginning of coordinates, and the center of circumference $\gamma$ is the point with the complex coordinate $u$.

It was proved in [4], that if the loading is concentrated at the point $z_{0}$, the equation of the blend of the surface has a form

$$
w(z)=\frac{P}{16 \pi D}\left[\left(1-\left|z_{0}\right|^{2}\right)\left(1-|z|^{2}\right)-\left|z-z_{0}\right|^{2} \ln \frac{\left|z-z_{0}\right|^{2}}{\left|1-\bar{z}_{0} z\right|^{2}}\right] .
$$

Hence, if $t$ is a point of the circumference $\gamma$, the equation of the blend of the plate has a form

$$
w(z)=\frac{P}{16 \pi D} \int_{\gamma}\left[\left(1-|t|^{2}\right)\left(1-|z|^{2}\right)+|z-t|^{2} \ln \frac{|z-t|^{2}}{|1-\bar{t} z|^{2}}\right] d l
$$

where $d l$ is an element of the length of the $\operatorname{arc} \gamma$. Let us compute the integral

$$
I_{1}=\int_{\gamma}\left[\left(1-|t|^{2}\right)\left(1-|z|^{2}\right)\right] d l
$$


We rewrite an element of the arc $d l$ in the form

$$
d l=r d \varphi=\frac{i r^{2} e^{i \varphi} d \varphi}{i r e^{i \varphi}}=\frac{r d(t-u)}{i(t-u)}=\frac{i r d t}{t-u} .
$$

Due to equality $(t-u)(\bar{t}-\bar{u})=r^{2}$ we have $\bar{t}=\frac{r^{2}}{t-u}+\bar{u}$. Hence

$$
\begin{aligned}
I_{1} & =\int_{\gamma}\left[\left(1-|t|^{2}\right)\left(1-|z|^{2}\right)\right] d l \\
& =-\left(1-|z|^{2}\right)=\int_{\gamma} \frac{i r}{t-u}\left[1-t\left(\frac{r^{2}}{t-u}+u\right)\right] d t .
\end{aligned}
$$

Applying the theorem about the residues (see [2]), we obtain

$$
I_{1}=2 \pi r\left(1-r^{2}-u^{2}\right)\left(1-|z|^{2}\right) .
$$

Now let us find the integral $\int|t-z|^{2} \ln |t-z|^{2} d l$. Firstly, we suppose that $|z-u|<r$. Then

$$
\begin{aligned}
|t-z|^{2} & =|(t-u)-(z-u)|^{2}=[(t-u)-(z-u)][(\bar{t}-\bar{u})-(\bar{z}-\bar{u})] \\
& =(t-u)(\bar{t}-\bar{u})\left(1-\frac{z-u}{t-u}\right)\left(1-\frac{\bar{z}-\bar{u}}{\bar{t}-\bar{u}}\right) \\
& =r^{2}\left(\left(1-\frac{z-u}{t-u}\right)\left(1-\frac{(\bar{z}-\bar{u})(t-u)}{r^{2}}\right) .\right.
\end{aligned}
$$

Hence

$$
\begin{aligned}
& I_{21}=\int_{\gamma}|t-z|^{2} \ln |t-z|^{2} d l \\
& =\int_{\gamma}|t-z|^{2} \ln \left[r^{2}\left(1-\frac{z-u}{t-u}\right)\left(1-\frac{\bar{z}-\bar{u}}{\bar{t}-\bar{u}}\right)\right] d l \\
& =\ln r^{2} \int_{\gamma}|t-z|^{2} d l+2 \operatorname{Re} \int_{\gamma}|t-z|^{2} \ln \left(1-\frac{(\bar{z}-\bar{u})(t-u)}{r^{2}}\right) d l \\
& =r^{2} \ln r^{2} \int_{\gamma}\left(1-\frac{z-u}{t-u}\right)\left(1-\frac{(\bar{z}-\bar{u})(t-u)}{r^{2}}\right) \frac{-i r}{t-u} d t \\
& +2 r^{2} \operatorname{Re} \int_{\gamma}\left(1-\frac{z-u}{t-u}\right)\left[1-\frac{(\bar{z}-\bar{u})(t-u)}{r^{2}}\right] \ln \left(1-\frac{(\bar{z}-\bar{u})(t-u)}{r^{2}}\right) \frac{i r d t}{t-u} .
\end{aligned}
$$


On the method for the solution of one problem of the elasticity theory 141

Applying the theorem about the residues, we obtain the equality

$$
I_{21}=2 \pi r \ln r\left(r^{2}+|z-u|^{2}\right)+4 \pi r|z-u|^{2} .
$$

Now let us suppose that $|z-u|>r$. Then

$$
\begin{aligned}
|z-t|^{2} & =[(z-u)-(t-u)][(\bar{z}-\bar{u})-(\bar{t}-\bar{u})] \\
& =(z-u)(\bar{z}-\bar{u})\left(1-\frac{1-u}{z-u}\right)\left(1-\frac{\bar{t}-\bar{u}}{z-u}\right) \\
& =|z-u|^{2}\left(1-\frac{1-u}{z-u}\right)\left(1-\frac{r^{2}}{(z-u)(t-u)}\right)
\end{aligned}
$$

Thus we have proved that $I_{31}=I_{32}=I_{3}$.

\section{MAIN FORMULA}

We have proved that the equation of the blend of the plate has a form

$$
\begin{aligned}
& \begin{aligned}
w= & \frac{P}{16 \pi D}\left[2 \pi r\left(1-r^{2}-|u|^{2}\right)\left(1-|z|^{2}\right)+2 \pi r \ln r^{2}\left(r^{2}+|z-u|^{2}\right)\right.
\end{aligned} \\
& \left.\quad+4 \pi r|z-u|^{2}-2 \pi r\left(r^{2}+|z-u|^{2}\right) \ln |1-u \bar{z}|^{2}-4 \pi r^{3} \operatorname{Re} \frac{\bar{z}(z-u)}{1-\bar{z} u}\right], \\
& \text { if }|z-u|<r, \text { and } \\
& \begin{aligned}
w=\frac{P}{16 \pi D} & {\left[2 \pi r\left(1-r^{2}-|u|^{2}\right)\left(1-|z|^{2}\right)+2 \pi r \ln |z-u|^{2}\left(r^{2}+|z-u|^{2}\right)\right.}
\end{aligned} \\
& \left.\quad+4 \pi r^{3}-2 \pi r\left(r^{2}+|z-u|^{2}\right) \ln |1-u \bar{z}|^{2}-4 \pi r^{3} \operatorname{Re} \frac{\bar{z}(z-u)}{1-\bar{z} u}\right],
\end{aligned}
$$

if $|z-u|>r$.

Let assume that the loading $P$ is a real valued function of the coordinates $P=P(x, y)$.

We denote

$$
P_{1}(x, y)=-\frac{\partial w_{0}}{\partial x} \frac{1}{D}, \quad P_{2}(x, y)=-\frac{\partial w_{0}}{\partial y} \frac{1}{D}
$$

where $D$ is a cylindrical rigidity of the plate. Then on the unit circumference

$$
\begin{aligned}
& P_{1}(x, y)=P_{1}\left(\frac{t+\bar{t}}{2}, \frac{t-\bar{t}}{2 i}\right)=P_{1}\left(\frac{t+\frac{1}{t}}{2}, \frac{t-\frac{1}{t}}{2 i}\right)=c_{1}(t), \\
& P_{2}(x, y)=P_{2}\left(\frac{t+\bar{t}}{2}, \frac{t-\bar{t}}{2 i}\right)=P_{2}\left(\frac{t+\frac{1}{t}}{2}, \frac{t-\frac{1}{t}}{2 i}\right)=c_{2}(t),
\end{aligned}
$$


where $|t|=1$. In this case for computation of the integrals in (1.21) and (1.23) we can use the theorem about residues.

Let the loading $q(x, y)$ be an arbitrary twice continuously differentiable function of coordinates. Then for computation of integrals in (1.21) and (1.23) we can use the approximate method, described in our article [3].

\section{REFERENCES}

[1] V.R. Kristalinskii. About one method for the approximate computation of the Cauchytype integrals. Polyanalytic functions: boundary characteristics and boundary value problems, $34-38$, 1997. (in Russian)

[2] M.A. Lavrentiev and Shabat B.V. The methods of the theory of the functions of complex variable. L.: Fizmatgiz, 1958. (in Russian)

[3] K.M. Rasulow and V.R. Kristalinskii. About one method for the approximate solution of the byharmonic problems. In: Proceedings of the international conference, devoted to the 75-th anniversary of M.B. Balk. Smolensk, 27 - 29, 1998. (in Russian)

[4] S.P. Timoshenko and Vojnovsky-Kriger S. Plates and shells. L.: Fizmatgiz, 1963. (in Russian)

[5] I.N. Vekua. Complex representation of the solutions of the elliptic differential equations and its application to the boundary value problems. In: Proceedings of the Tbilisi mathematical institute, volume VII, 161 - 253, 1939. (in Russian)

\section{Apie vieno uždavinio elastiškumo teorijoje sprendimo metodą}

\section{V.R. Kristalinskii}

Straipsnyje kompleksinio kintamojo analizès ir kompiuterinès algebros metodai taikomi spendžiant eilę uždavinių, kurių tikslas surasti apskričios įtvirtintos plokštelès lygtis, kai ją veikia ivairaus tipo apkrovos. Gauti rezultatai testuojami pavyzdžiais. Gauta keletas nauju rezultatų. Išnagrinètas atvejis, kai apkrovos pasiskirsčiusios nekoncentriškais apskritimais, atkarpa arba laisvai bet kokiu būdu visoje plokštelèje. 